\title{
Effect of probiotics, Saccharomyces spp.Kb-5 and Kb-8, in diets on growth performance and cholesterol levels in ducks
}

\author{
I.G.N.G. Bidura\#, N.W. Siti \& I.B.G. Partama \\ Faculty of Animal Science, Udayana University, Jalan PB Soedirman, Denpasar, Bali, Indonesia
}

(Received 19 June 2018; Accepted 23 August 2018; First published online 3 April 2019)

\author{
Copyright resides with the authors in terms of the Creative Commons Attribution 4.0 South African Licence. \\ See: http://creativecommons.org/licenses/by/4.0/za \\ Condition of use: The user may copy, distribute, transmit and adapt the work, but must recognise the authors and \\ the South African Journal of Animal Science.
}

\begin{abstract}
The study was conducted to determine the effect of the probiotics, Saccharomyces spp.Kb-5 and Saccharomyces spp.Kb-8, on growth performance, carcass characteristics, serum and meat cholesterol levels in ducks. Two hundred and forty 1-day-old healthy male ducks were randomly allocated to four treatment groups: A) basal diet (control), B) basal diet $+0.20 \%$ Saccharomyces spp.Kb-5, C) basal diet + $0.20 \%$ Saccharomyces spp.Kb-8, and D) basal diet $+0.10 \%$ Saccharomyces spp.Kb-5 $+0.10 \%$ Saccharomyces spp.Kb-8. Growth performance, carcass characteristics, and serum and meat cholesterol levels were determined when the ducks were 56 days old. Saccharomyces spp.Kb-5 and Saccharomyces spp.Kb-8, and the incombination, increased bodyweight gains, feed efficiencies and carcass weight significantly, but not affect the amount of feed consumed. The administration of Saccharomyces spp. results in significant lower serum and meat cholesterol concentrations compared to the control. It was concluded that the addition of Saccharomyces spp.Kb-5 and Saccharomyces spp.Kb-8, and the incombination, in the diet increased growth performances, feed efficiency and carcass weight, and decreased serum and meat cholesterol concentrations in male ducklings.
\end{abstract}

Keywords: carcass characteristics, digestibility, feed efficiencies

\#Corresponding author: bidura_unud@yahoo.com

\section{Introduction}

The manipulation of the gut function and microbial habitat of domestic animals with feed additives has been recognized as an important tool for improving growth performance and feed efficiency. Antibiotics have been used widely as feed additives for broiler chickens, owing to their ability to manipulate the intestinal microbial population, to improve feed conversion ratio (FCR) and to promote growth. However, there is growing concern about possible antibiotic residue effects and the development of drug-resistant bacteria, owing to the continuous feeding of antibiotics to livestock at sub-therapeutic levels (Chen et al., 2017).

Feed additives such as live probiotics can balance microorganism populations in the digestive tract, improve feed efficiency by $>15 \%$ and provide economic benefits for farmers that raise starter ducks (Zurmiati et al., 2017). According to Chen et al. (2017), two possible mechanisms for the beneficial effects of probiotic bacteria on gastrointestinal disturbances are: i) the production of antimicrobial compounds such as lactic acid and bacteriocins and ii) their adherence to the mucosa and co-aggregation to form a barrier that prevents colonization of pathogens. Supplementation of probiotics (Bacillus species and Saccharomyces boulardii) at $150 \mathrm{~g} /$ ton to replace antibiotics in broiler feed as a growth promoter, was found to enhance immune system responses and induce beneficial modulations in caecal microflora in broiler chickens (Manafi et al., 2018).

Previous studies have indicated that probiotics enhanced the immune system, increased body weight gain (BWG), improved feed efficiency (Bidura et al., 2012; Bidura et al., 2016; Hasan et al., 2016), improved the nutrient quality of feed (Bidura et al., 2014; Bidura et al., 2015; Bidura \& Siti, 2017), decreased abdominal fat, and reduced serum (Puspani et al., 2016; Bidura et al., 2016; Ristiani et al., 2017) and egg cholesterol concentrations in ducks and broilers (Bidura et al., 2016). Probiotics also have beneficial effects on the growth performance, blood parameters and IgG stimulation in weaned piglets (Dlamini et al., 2017).

The addition of probiotics to the drinking water of Pitalah ducks significantly decreased feed consumption, feed conversion and small intestinal acidity, and increased income over feed cost and total 
small intestinal Bacillus spp. colony counts (Zurmiati et al., 2017). Digestibility coefficients of dry matter (DM), organic matter $(\mathrm{OM})$, crude protein (CP), neutral detergent fibre and gross energy were higher in probiotics groups than in a control group (Phuoc \& Jamikorn, 2017).

Previous research isolated yeast Saccharomyces spp. from buffalo rumen. It has enzyme activity (CMC-ase) and passed the test as a probiotic agent, that is, it passed the temperature, $\mathrm{pH}$, acid and bile salt tests, and is capable of deconjugating bile acids. It also has the ability to degrade crude fibre in feed (Bidura \& Siti, 2017). Saccharomyces spp.Kb-05 and Saccharomyces spp.Kb-08 can increase CP and metabolizable energy of rice bran (Bidura \& Siti, 2017).

Multi-species probiotic preparations are thought to be more effective than single-strain probiotics. Probiotic yeasts such as Saccharomyces have been shown to stimulate the immune system of chicks without decreasing growth performance (Bai et al., 2013). Microbes can be selected as candidate probiotics and isolated from buffalo rumen liquid, so that when tested on ducks, they could grow and thrive in the intestine. Therefore, this experiment aimed to evaluate probiotics, Saccharomyces spp.Kb-5, Saccharomyces spp.Kb-8 and their combination, on growth performance, carcass weight, and serum and meat cholesterol concentrations in ducks.

\section{Material and Methods}

Two hundred and forty 1-day-old healthy male Bali ducks (Anas sp.) were used in a completely randomized experimental design. All diets were isonitrogenous and isoenergetic and were formulated to meet the nutrient requirements for poultry (NRC, 1994) for the eight weeks of the experiment. The ingredients and chemical compositions of the feed are presented in Table 1.

Table 1 Ingredients and calculated nutrient content of the feed of growing male Bali ducklings up to eight weeks old

\begin{tabular}{lcc}
\hline Basal diets & Compositions \\
\hline Ingredients & & \\
Yellow corn & & 57.27 \\
Rice bran & 16.00 \\
Soybean & & 4.70 \\
Pollard & 7.10 \\
Fish meal & 14.32 \\
Palm oil & 0.31 \\
NaCl & & 0.30 \\
\hline Total & & 100 \\
\hline Chemical composition * & & \\
Metabolizable energy & & \\
Crude protein & $(\mathrm{kcal} / \mathrm{kg})$ & 2900.03 \\
Crude fibre & $(\%)$ & 18.0 \\
Ether extract & $(\%)$ & 4.15 \\
Calcium & $(\%)$ & 7.04 \\
Phosphorus (available) & $(\%)$ & 1.15 \\
Arginine & $(\%)$ & 0.68 \\
Lysine & $(\%)$ & 1.27 \\
Methionine+cysteine & $(\%)$ & 1.32 \\
Tryptophan & $(\%)$ & 0.78 \\
& $(\%)$ & 0.20 \\
\hline
\end{tabular}

* Based on calculation according to Scott et al. (1982)

All birds were given a commercial feed for ducks, which contained $2900 \mathrm{kcal} / \mathrm{kg}$ of metabolizable energy (ME), $18 \% \mathrm{CP}, 1.15 \%$ calcium (Ca) and $0.68 \%$ available phosphorus. The ducks were randomly 
allocated to four treatment groups: A) basal diet (control), B) basal diet $+0.20 \%$ Saccharomyces spp. Kb-5, C) basal diet $+0.20 \%$ Saccharomyces spp.Kb-8, and D) basal diet $+0.10 \%$ Saccharomyces spp.Kb-5 + $0.10 \%$ Saccharomyces spp.Kb-8. Each treatment consisted of six replicate pens with 10 birds per pen at $150 \times 50 \times 45 \mathrm{~cm}$ (length $\times$ width $\times$ height). The diet was in mash form and the birds had free access to feed and water throughout the experiment.

The probiotic was prepared in the Laboratory of Nutrition and Technology at Faculty of Animal Science, University of Udayana. Each $1 \mathrm{~g}$ of culture contains at least $10^{7} \mathrm{CFU}$ of Saccharomyces spp.

Continuous lighting was provided throughout the experiment. Body weight, weight gain, feed intake and FCR for birds were recorded separately from week 1 until week 8. Feed consumption (gram per bird) was recorded weekly at each replication by weighing the remaining diet. The total feed intake for each replicate was measured during the experiment. FCR was calculated as gram of feed consumed per gram BWG.

At the end of the experiment, the birds were weighed and feed consumption was recorded to calculate average daily gain (ADG), average daily feed intake based on dry matter (DM) and FCR (feed DM intake/weight gain). The birds were deprived of feed for 12 hours (water was provided) before weighing to ensure that the digestive tracts of the birds (Wang et al., 2017) were emptied. Mortality was recorded daily as it occurred. Any bird that died, was removed, and weighed to adjust the FCR.

At the end of the study ( 8 weeks), the ducks were slaughtered. Two birds per unit in the experiment that were close to the average live body weight (BW) were selected. After weighing, legs were banded for identification. About $4 \mathrm{~mL}$ blood per bird was taken from the wing vein with a sterile syringe. These blood samples were kept in sterile $5 \mathrm{~mL}$ centrifugal tubes. Blood samples were maintained at room temperature for 1 - 2 hours before being centrifuged for $10 \mathrm{~min}$ at approximately $3000 \mathrm{~g}$. After blood collection, the same birds were weighed individually to measure the slaughter weight. All birds were processed by trained personnel of the plant in a commercial abattoir.

Birds were weighed to the nearest gram, subjected to 24 hour-feed withdrawal with free access to water, reweighed, and slaughtered by neck cutting. They were bled immediately through cutting the carotid arteries and partially slicing the neck with a manual neck cutter. After five minutes of bleeding, each bird was scalded, defeathered and eviscerated after the head and legs were removed. The carcass without giblets was weighed, and expressed as a percentage of live weight, which was regarded as carcass yield (Zurmiati et al., 2017). After being stored in a cold chamber at $4{ }^{\circ} \mathrm{C}$ overnight, the birds were weighed separately to estimate dressing weight. The dressed percentage was calculated by dividing the dressing weight by the slaughter weight. The half-eviscerated weight was evaluated as the weight of carcass without trachea, oesophagus, pseudo-crop, guts, spleen, pancreas, gall bladder, reproduction organs and the chime and gizzard (Wang et al., 2017). The eviscerated weight was quantified when the weights of heart, liver, proventriculus, gizzard, lungs and abdominal fat were subtracted from the half-eviscerated weight. The head, neck, wings and feet were cut from the atlanto-occipital articulations, scapula, articulatio humeri and ankle joint, respectively. The pectoral and leg muscles were stripped to exclude the skin, subcutaneous fat, bones and tendons. The percentage of breast meat was a sum of the breast meat divided by carcass weight and expressed as $\mathrm{g} / 100 \mathrm{~g}$ of carcass weight. Furthermore, meat cholesterol was evaluated from samples of breast meat. These samples were blended until smooth and homogeneous, and kept for cholesterol analysis. The blood samples were allowed to clot in a sample bottle and the serum was used to determine total serum cholesterol concentration. Analysis of the cholesterol level was according to the LiebermanBurchard method (Lieberman \& Burchard, 1980) using a commercial kit (Ezema \& Eze, 2015).

To determine the digestibility of DM and OM of each experimental diet, $100 \mathrm{~g}$ of a diet was used. The birds were deprived of feed for 24 hours to ensure that their alimentary tracts were empty of feed residue. They were then force-fed with the specific amounts of diets (all treatments). A stainless steel funnel with a 40-cm stem was used to force-feed (Mustafa et al., 2004). Water was available ad libitum during the experiment. Total excreta were collected in plastic trays. The excreta samples were frozen, then allowed to come to equilibrium with atmospheric moisture, and then weighed and ground through a 1-mm sieve. Samples of excreta and diets were subjected to appropriate analyses to determine DM and OM. Dry matter, $\mathrm{OM}$ and ash determinations were done according to the Association of Official Analytical Chemists (AOAC, 2005). All assays were conducted in triplicate.

All data were analysed using ANOVA to determine the differences among treatments. If differences were found, then further analysis was performed with Duncan's multiple range test. 


\section{Results}

Body weight gain, feed consumption, FCR, DM and OM digestibility in the groups that were fed the experimental diets are shown in Table 2. The treated ducks exhibited higher growth rates and feed/gain than the control birds in terms of final BW and BWG. No significant differences in the feed consumption and feed digestibility were observed among the dietary groups.

Body weight gain in ducks fed the diets containing $0.20 \%$ Saccharomyces spp.Kb-5, Saccharomyces spp.Kb-8 or the incombination were significantly higher $(P<0.05)$ compared with the control. There were no significant differences in feed consumption during the experiment. Feed/gain in the groups fed the probiotics was superior to that of the control.

Table 2 Effects of probiotics, Saccharomyces spp.Kb-5 and Saccharomyces spp.Kb-8, in diets on growth performance and feed digestibility in ducks

\begin{tabular}{lccccc}
\hline \multirow{2}{*}{ Variables } & \multicolumn{4}{c}{ Groups $^{1}$} & \multirow{2}{*}{ SEM $^{2}$} \\
\cline { 2 - 5 } & A & B & C & D & \\
\hline Initial bodyweight (g) & $54.9^{\mathrm{a}}$ & $56.9^{\mathrm{a}}$ & $55.3^{\mathrm{a}}$ & $55.7^{\mathrm{a}}$ & 0.863 \\
Final bodyweight (g) & $1382.5^{\mathrm{a}}$ & $1457.9^{\mathrm{b}}$ & $1491.0^{\mathrm{b}}$ & $1508.5^{\mathrm{b}}$ & 20.90 \\
Bodyweight gains (g/bird/56 days) & $1327.6^{\mathrm{a}}$ & $1400.9^{\mathrm{b}}$ & $1435.7^{\mathrm{b}}$ & $1452.8^{\mathrm{b}}$ & 21.05 \\
Feed consumption (g/bird/56 days) & $3332.3^{\mathrm{a}}$ & $3320.2^{\mathrm{a}}$ & $3316.5^{\mathrm{a}}$ & $3326.9^{\mathrm{a}}$ & 25.916 \\
Water consumption (L/bird/56 days) & $11.67^{\mathrm{a}}$ & $10.87^{\mathrm{a}}$ & $11.07^{\mathrm{a}}$ & $10.59^{\mathrm{a}}$ & 1.052 \\
Feed conversion ratio (feed consumption: bodyweight gain) & $2.51^{\mathrm{a}}$ & $2.37^{\mathrm{b}}$ & $2.31^{\mathrm{b}}$ & $2.29^{\mathrm{b}}$ & 0.031 \\
Dry matter digestibility (\%) & $67.9^{\mathrm{a}}$ & $69.8^{\mathrm{a}}$ & $68.85^{\mathrm{a}}$ & $70.1^{\mathrm{a}}$ & 2.038 \\
Organic matter digestibility (\%) & $68.4^{\mathrm{a}}$ & $70.2^{\mathrm{a}}$ & $69.8^{\mathrm{a}}$ & $71.2^{\mathrm{a}}$ & 2.371
\end{tabular}

\footnotetext{
${ }^{1}$ A: basal diet (control); B: basal diet $+0.20 \%$ Saccharomyces spp.Kb-5; C: basal diet+0.20\% Saccharomyces spp.Kb-8; and D: basal diet $+0.10 \%$ Saccharomyces spp.Kb-5+0.10\% Saccharomyces spp.Kb-8

${ }^{2}$ SEM: standard error of treatment means

3 Means within rows with different superscripts are significantly different $(P<0.05)$
${ }^{3}$ stand
}

No significant differences were observed in carcass percentages (carcass weight/body weight $x$ $100 \%)($ Table 2). The treated ducks had higher $(P<0.05)$ carcass weights and breast meat $(\mathrm{g} / 100 \mathrm{~g}$ carcass weight) than the control birds.

Table 3 Effects of probiotics, Saccharomyces spp.Kb-5 and Saccharomyces spp.Kb-8, in diets on carcass weight, serum and meat cholesterol concentrations in ducks

\begin{tabular}{|c|c|c|c|c|c|}
\hline \multirow{2}{*}{ Variables } & \multicolumn{4}{|c|}{ Groups $^{1}$} & \multirow{2}{*}{$\mathrm{SEM}^{2}$} \\
\hline & A & B & C & D & \\
\hline Carcass weight (g/bird) & $750.7^{\mathrm{a}}$ & $832.7^{b}$ & $850.8^{\mathrm{b}}$ & $863.7^{b}$ & 18.039 \\
\hline Carcass yield (carcass weight/final body weight $x$ 100) (\%) & $54.3^{\mathrm{a}}$ & $57.2^{\mathrm{a}}$ & $57.1^{\mathrm{a}}$ & $57.3^{\mathrm{a}}$ & 0.582 \\
\hline Breast meat (g/100 g carcass weight) ${ }^{\star} 100$ & $5.19^{\mathrm{a}}$ & $5.71^{\mathrm{b}}$ & $5.69^{\mathrm{b}}$ & $5.82^{\mathrm{b}}$ & 0.149 \\
\hline Serum cholesterol (mg/dL) & $158.0^{\mathrm{a}}$ & $142.9^{\mathrm{b}}$ & $145.9^{b}$ & $140.1^{\mathrm{b}}$ & 3.083 \\
\hline Meat cholesterol (mg/100 g) & $76.9^{\mathrm{a}}$ & $69.5^{\mathrm{b}}$ & $70.3^{\mathrm{b}}$ & $68.8^{\mathrm{b}}$ & 1.207 \\
\hline
\end{tabular}

\footnotetext{
${ }^{1}$ A: basal diet (control); B: basal diet+0.20\% Saccharomyces spp.Kb-5; C: basal diet+0.20\% Saccharomyces spp.Kb-8; and D: basal diet+0.10\% Saccharomyces spp.Kb-5+0.10\% Saccharomyces spp.Kb-8, respectively.

${ }^{2}$ SEM: standard error of treatment means

${ }^{3}$ Means with different superscripts within rows are significantly different $(P<0.05)$
} 
The results showed that additional khamir Saccharomyces spp. (Groups B, C and D) in diets resulted in a significant $(P<0.05)$ decrease in concentration of cholesterol in the serum and meat of the birds (Table 3). The lowest mean serum cholesterol concentration was found in Group D (140.1 mg/dL) which was $11.4 \%$ lower than the control. In Group B the serum cholesterol level was $142.9 \mathrm{mg} / \mathrm{dL}$ or $9.6 \%$ lower than in Group A, and in Group C $145.9 \mathrm{mg} / \mathrm{dL}$ (7.66\% lower than in Group A). Group A (control) recorded a serum cholesterol level of $158.0 \mathrm{mg} / \mathrm{dL}$. The serum cholesterol concentrations of Groups B, C and D did not differ significantly. The cholesterol concentrations of the meat from Groups $\mathrm{B}, \mathrm{C}$ and $\mathrm{D}$ were significantly $(P<0.05)$ lower than in Group A (Table 3).

\section{Discussion}

Saccharomyces spp. as a potential probiotic in duck feed influenced BWG, but did not affect feed consumption. The results confirm that the probiotic increased BWG and FCR (feed/gain). Ramasamy et al. (2010) reported that supplementation of probiotic cultures did not influence feed intake. The results of BWG analysis indicated that probiotics, Saccharomyces spp.Kb-5 and Saccharomyces spp.Kb-8 and their combinations, showed better growth performance than the control group during the experiment, and improved FCR. The improved FCR in the groups that were fed probiotics, as compared with the control group, was the result of the higher weight gains, since all treatments had similar feed intakes. Husain et al. (2017) reported that the effect of probiotic that was isolated from the domestic chicken provided increased BWG and meat quality, FCR and growth performance. The beneficial effects of supplementing probiotic were manifested mainly in live BW and growth rate traits. Inclusion of the probiotic in the poultry diet improved broiler performance (Sikandar et al., 2017; Manafi et al., 2018). Chen et al. (2009) reported that, currently, Bacillus, Lactobacillus and Saccharomyces are the major strains that are utilized in poultry. However, in other studies, dietary probiotics had no significant effect on live BW, BWG or FCR (Aliakbarpour et al., 2012; Fathi et al., 2017; Zurmiati et al., 2017). These authors reported that production parameters were not affected by dietary probiotic or yeast supplementation. These inconsistent results of probiotic supplementation may be because of differences in number of suitable living bacteria, animal age and supplementation strains (Chen et al., 2017).

Inclusion of Saccharomyces spp. as a potential probiotic in duck feed significantly affected FCR and feed digestibility (DM and OM digestibility) compared with control birds. Zurmiati et al. (2017) and Hasan et al. (2016) reported that supplementation of Lactobacillus acidophilus alone or in combination with $B$. subtilis at a half dose could enhance the numbers of gut beneficial bacteria populations, nutrient digestibility, caecal fermentation, FCR and growth performance in chickens, but in rabbits receiving $B$. subtilis alone, performed no different from the controls without probiotic (Phuoc \& Jamikorn, 2017), while pigs receiving probiotics had higher final BWs and increased BWG (Tufarelli et al., 2017).

Inclusion of probiotic in the diets significantly increased goblet cell number and villus length (Aliakbarpour et al., 2012). Azzam et al. (2011) reported that various factors, such as colonization of microbes in the gut, affect the production, secretion and composition of mucin. Mucin is the main product of mucose epithelial cell of the avian gastro intestinal tract (Iwashita et al., 2003) and consists of a peptide backbone containing alternating glycosylated and non-glycosylated domains (Uni et al., 2003). Therefore, this is the first line of host intestinal defence, and could influence nutrient digestion and absorption. The higher synthesis of the mucin gene after probiotic administration may affect bacterial interactions positively in the digestive tract and intestinal mucosal cell proliferation, and consequently improved nutrient absorption (Aliakbarpour et al., 2012). Similar results were obtained when fermented feed with a probiotic in a dry form was used in the diet of Akar Putra chicken (Lokman et al., 2015).

In the present study, the treated ducks in Groups B, C and D had significantly higher carcass weights and breast meat (g/100 $\mathrm{g}$ carcass weight) than Group A. Khaksefidi \& Rahimi (2005) reported that the leg and breast meat of probiotic-fed chickens were higher in moisture, protein and ash, and lower in fat percentage compared with the leg and breast meat of the control. Serum and meat cholesterol levels were significantly lower in ducks fed with diets containing khamir Saccharomyces spp. According to Alkhalf et al. (2010), it is suggested that a probiotic (Lactobacillus) reduces the cholesterol in the blood by deconjugating bile salts in the intestine, thereby preventing them from acting as precursors in cholesterol synthesis. The Saccharomyces spp. was found to have high bile salt hydrolytic activity (Bidura \& Siti, 2017). In the current study the reduction in circulating cholesterol when yeast (Saccharomyces cerevisiae) was supplemented, was remarkable and agrees with the results of other researchers. Kusumawati et al. (2003) reported that probiotics have the ability to lower serum cholesterol levels. Ezema \& Eze (2015) reported that probiotic inclusion of $1.0 \mathrm{~g} / \mathrm{kg}$ of feed was recommended for effective reduction in serum and egg cholesterol levels. Tang et al. (2016) recorded that feeding laying hens with probiotics significantly decreased egg yolk 
cholesterol, and total saturated fatty acids compared with the control. De Smet et al. (1998) reported that probiotics could contribute to the regulation of serum cholesterol concentration by deconjugating bile acids. Since the excretion of deconjugated bile acid is enhanced and cholesterol is its precursor, more molecules are spent on recovery of bile acids. In contrast, An et al. (2008) and Kalavathy et al. (2003) reported no significant differences in the breast muscle, and in the activities of serum enzymes and concentrations of various cholesterol fractions. The inconsistent results of probiotic supplementation may be owing to differences in numbers of suitable living bacteria, animal age and supplementation strains (Chen et al., 2017). It is possible that probiotic efficacy may depend on factors such as microbial species composition (single or multi-strain mixture) and viability, supplementation level, application method, frequency of application, overall diet, bird age, overall farm hygiene and environmental stress factors (Zhang \& Kim, 2014). No clear mechanisms have been reported to be responsible for the reduction of lipid synthesis by prebiotics and probiotics. It might in part be owing to an increase in beneficial bacteria, such as Lactobacillus, which decrease the activity of acetyl-CoA carboxylase, which is the rate-limiting enzyme in fatty acid synthesis (Zurmiati et al., 2017).

\section{Conclusion}

It is concluded that supplementation of the probiotics, Saccharomyces spp.Kb-5, Saccharomyces spp.Kb-8 and the combination, to diets, increased growth performance, feed efficiency and carcass weight, and decreased serum and meat cholesterol concentrations in ducks.

\section{Acknowledgements}

The authors would like to thank to the Head of Research and Public Service Department and Rector of Udayana University for their support during this study including research funding.

\section{Authors' Contributions}

IGNG.B was the principal investigator of this project, and the writer of the manuscript. NWS and IBGP designed the project, and were involved in specimen collection (sampling) and laboratory work.

\section{Conflict of Interest Declaration}

The authors certify that there is no conflict of interest with any financial organization regarding the material discussed in the manuscript.

\section{References}

Aliakbarpour, H.R., Chamani, M., Rahimi, G., Sadeghi, A.A. \& Qujeq, D., 2012. The Bacillus subtilis and lactic acid bacteria probiotics influences intestinal mucin gene expression, histomorphology and growth performance in broilers. Asian-Austral. J. Anim. Sci. 25, 1285-1293.

Alkhalf, A., Alhaj, M. \& Al-Homidan, I. 2010. Influence of probiotic supplementation on blood parameters and growth performance in broiler chickens. Saudi J. Biol. Sci. 17, 219-225.

An, B.K., Cho, B.L., You, S.J., Paik, H.D., Chang, H.I., Kim, S.W., Yun, C.W. \& Kang, C.W., 2008. Growth performance and antibody response of broiler chicks fed yeast-derived $\beta$-glucan and single-strain probiotics. Asian-Austral. J. Anim. Sci. 21, 1027-1032.

AOAC. 2005. Official Methods of Analysis of AOAC International. 18th edition. Association of Official Analytical Chemists, Arlington, USA.

Azzam, M.M.M., Zou, X.T., Dong, X.Y. \& Xie, P., 2011. Effect of supplemental L-threonine on mucin 2 gene expression and intestine mucosal immune and digestive enzymes activities of laying hens in environments with high temperature and humidity. Poult. Sci. 90, 2251-2256.

Bai, S.P., Wu, A.M., Ding, X.M., Lei, Y., Bai, J., Zhang, K.Y. \& Chio, J.S., 2013. Effects of probiotic-supplemented diets on growth performance and intestinal immune characteristics of broiler chickens. Poult. Sci. 92, 663-670.

Bidura, I.G.N.G. \& Siti, N.W., 2017. Selection and implementation of probiotics Saccharomyces spp.Kb-05 and Saccharomyces spp. Kb-08 isolated from buffalo ruminants to increase the nutritional value of rice bran. J. Biol. Chem. Res. 34, 866-877.

Bidura, I.G.N.G., Suyadnya, I.P., Mahardika, I.G., Partama, I.B.G., Oka, I.G.L. \& Aryani, I.G.A.I., 2012. The implementation of Saccharomyces spp.n-2 isolate culture (isolation from traditional yeast culture) for improving feed quality and performance of male Bali duckling. Agric. Sci. Res. J. 2, 486-492.

Bidura, I.G.N.G., Candrawati, D.P.M.A. \& Partama, I.B.G., 2014. Selection of Saccharomyces spp. isolates (isolation from colon beef of Bali cattle) as probiotics agent and colon cancer prevention and its effect on pollard quality as feed. J. Biol. Chem. Res. 31, 1043-1047

Bidura, I.G.N.G., Candrawati, D.P.M.A. \& Warmadewi, D.A., 2015. Selection of Khamir Saccharomyces spp. isolated from colon of native chickens as a probiotics properties and has CMC-ase activity. J. Biol. Chem. Res. 32 , 683-699.

Bidura, I.G.N.G., Partama, I.B.G., Putra, D.K.H. \& Santoso, U., 2016. Implementation on diet of probiotic Saccharomyces spp.SB-6 isolated from colon of Bali cattle on egg production and egg cholesterol concentration of Lohmann brown laying hens. Int. J. Curr. Microbiol. App. Sci. 32 (2), 683-699. 
Chen, C.Y., Chen, S.W. \& Wang, H.T., 2017. Effect of supplementation of yeast with bacteriocin and Lactobacillus culture on growth performance, cecal fermentation, microbiota composition, and blood characteristics in broiler chickens.Asian-Austral. J. Anim. Sci. 30, 211-220.

Chen, K.L., Kho, W.L., You, S.H., Yeh, R.H., Tang, S.W. \& Hsieh, C.W., 2009. Effects of Bacillus subtilis var. natto and Saccharomyces cerevisiae mixed fermented feed on the enhanced growth performance of broilers. Poult. Sci. 88, 309-315.

De Smet, I., Van Hoorde De Saaeyer, L., Van de Woeslyne, M. \& Verstraele, W., 1998. Cholesterol lowering in pigs through enhanced bile salt hydrolase activity. Br. J. Nutr. 185-194.

Dlamini, Z.C., Langa, R.L.S., Aiyegoro, O.A. \& Okoh, A.I., 2017. Effects of probiotics on growth performance, blood parameters, and antibody stimulation in piglets. S. Afr. J. Anim. Sci. 47, 81-87.

Ezema, C. \& Eze, D.C., 2015. Probiotic effect of yeast (Saccharomyces cerevisiae) on hen-day egg performance, serum and egg cholesterol levels in laying chicken. Pak. J. Nutr. 14 (1), 44-46.

Fathi, M.M., Ebeid, T.A., Al-Homidan, I., Soliman, N.K. \& Abou-Emera, O.K., 2017. Influence of probiotic supplementation on immune response in broilers raised under hot climate. Br. Poult. Sci. 6, 1-5.

Husain, D.R., Dwyana, Z., Ambeng, Anggraeni, A. \& Sulfahri, 2017. Evaluation of bacteria from Gallus domesticus as a potential probiotic in broiler chicks: Effects on growth performance and feed conversion ratio. Int. J. Poult. Sci. 16, 43-49.

Hasan, S.A.J., Lokman, I.H., Naji, S.A., Zuki, A.B.Z. \& Kassim, A.B., 2016. Effects of dietary supplementation of wet fermented feed with probiotic on the production performance of Akar Putra chicken. Asian J. Poult. Sci. 10, 72-77

Iwashita, J., Yukita, S., Hiroko, S., Nagatomo, T., Hiroshi, S. \& Tatsuya, A., 2003. mRNA of MUC2 is stimulated by IL-4, IL-13 or TNF-14 through a mitogen-activated protein kinase pathway in human colon cancer cells. Immunol. Cell Biol. 81, 275-282.

Kalavathy, R., Abdullah, N. \& Jalaludin, S., 2003. Effects of Lactobacillus cultures on growth performance, abdominal fat deposition, serum lipids and weight of organs of broiler chickens. Br. Poult. Sci. 44, 139-144.

Khaksefidi, A. \& Rahimi, S., 2005. Effect of probiotic inclusion in the diet of broiler chickens on performance, feed efficiency and carcass quality. Asian-Austral. J. Anim. Sci. 18, 1153-1156.

Kusumawati, N., Bettysri, L.J., Siswa, S., Ratih, D. \& Hariadi, R.D., 2003. Selection of lactic acid bacteria of indigenous as strain probiotic with ability to lower cholesterol. J. Microbiol. Indonesian 8, 39-43.

Lieberman, A. \& Burchard, R., 1980. Enzymatic method to determined cholesterol. Engl. J. Med. 271, 915-924.

Lokman, I.H., Jawad, S.H., Zuki, A.B.Z. \& Kassim, A.B., 2015. Effect of dry probiotic supplemented fermented feed on production performance of Akar Putra chicken. Int. J. Poult. Sci. 14, 420-426.

Mahfuz, S.U., Nahar, M.J., Mo, C., Ganfu, Z., Zhongjun, L. \& Hui, S., 2017. Inclusion of probiotic on chicken performance and immunity: A Review. Int. J. Poult. Sci. 16 (9), 328-335.

Manafi, M., Hedayati, M. \& Mirzaie, S., 2018. Probiotic Bacillus species and Saccharomyces boulardii improve performance, gut histology and immunity in broiler chickens. S. Afr. J. Anim. Sci. 48, 379-389.

Mustafa, M.F., Alimon, A.R., Zahari, M.W., Idris, I. \& Bejo, M.H., 2004. Nutrient digestibility of palm kernel cake for muscovy ducks. Asian-Austral. J. Anim. Sci. 17, 514-517.

National Research Council. 1994. Nutrient requirements of poultry. 9th edition. National Academy Press, Washington, DC., USA.

Phuoc, T.L. \& Jamikorn, U., 2017. Effects of probiotic supplement (Bacillus subtilis and Lactobacillus acidophilus) on feed efficiency, growth performance, and microbial population of weaning rabbits. Asian-Austral. J. Anim. Sci. 30, 198-205.

Puspani, E., Candrawati, D.P.M.A. \& Bidura, I.G.N.G., 2016. Implementation of probiotics cellulolitic B-7 bacteria (isolation from buffalo rumen) into ration on the performance, abdominal fat and serum cholesterol of duck. Int. J. Curr. Microbiol. App. Sci. 5 (11), 432-441.

Ramasamy, K., Abdullah, N., Wong, M.C., Karuthan, C. \& Ho, Y.W., 2010. Bile salt deconjugation and cholesterol removal from media by Lactobacillus strains used as probiotics in chickens. J. Sci. Food Agric. 90, 65-69.

Ristiani, N.M., Bidura, I.G.N.G. \& Warmadewi, D.A., 2017. The effect of Saccharomyces spp.Gb-9 (isolated from colon of native chicken) on the growth performance and meat cholesterol level in broilers. J. Biol. Chem. Res. 34 (1), 118-128.

Scott, M.L., Neisheim, M.C. \& Young, R.J., 1982. Nutrition of Chickens. 2nd edtion. M. L. Scott \& Assoc. Ithaca, New York, USA.

Sikandar, A., Zaneb, H., Younus, M., Masood, S., Aslam, A., Shah, M. \& Rehman, H., 2017. Growth performance, immune status and organ morphometry in broilers fed Bacillus subtilis-supplemented diet. S. Afr. J. Anim. Sci. 47, 378-388.

Tang, C., Hoo, P.C.X., Tan, L.T.H., Pusparajah, P. \& Khan, T.M., 2016. Golden needle mushroom: A culinary medicine with evidenced-based biological activities and health promoting properties. Front. Pharmacol. 7. 10.3389/fphar.2016.00474.

Tufarelli, V., Crovace, A.M., Rossi, G. \& Laudadio, V., 2017. Effect of a dietary probiotic blend on performance, blood characteristics, meat quality and faecal microbial shedding in growing-finishing pigs. S. Afr. J. Anim. Sci. 47, 875-882.

Uni, Z., Smirnov, A. \& Sklan, D., 2003. Pre- and post-hatch development of goblet cells in the broiler small intestine: Effect of delayed access to feed. Poult. Sci. 82, 320-327. 
Wang, S.P., Wang, W.J., Yang, D.S., Zhao, X.L., Luo, D.M. \& Guo, Y.B., 2017. Growth, carcass, and physiological traits of growing male China micro-ducks fed various levels of dietary crude fibre. Czech J. Anim. Sci. 62, 347-356.

Zhang, Z.F. \& Kim, I.H., 2014. Effects of multistrain probiotics on growth performance, apparent ileal nutrient digestibility, blood characteristics, cecal microbial shedding, and excreta odor contents in broilers. Poult. Sci. 93, 364-370.

Zurmiati, W., Abbas, M.H., Mahata, M.E. \& Fauzano, R., 2017. Effect of Bacillus amyloliquefaciens as a probiotic on growth performance parameters of Pitalah ducks. Int. J. Poult. Sci. 16, 147-153. 